\title{
España, Israel y Palestina: encuentros y desencuentros
}

\section{Ignacio Álvarez-Ossorio Alvariño ${ }^{1}$}

Universidad de Alicante

ialvarez@ua.es

RESUMEN: La politica exterior española hacia Oriente Medio ha sido condicionada por el conflicto palestino-israelí. Durante la etapa franquista se priorizaron las denominadas "políticas de sustitución» basadas en el fortalecimiento de relaciones con Latinoamérica y los países árabes para tratar de sortear el aislamiento internacional impuesto tras la Segunda Guerra Mundial. Durante la transición democrática, España tuvo que hacer frente a importantes retos: no sólo la universalización de las relaciones diplomáticas y su integración en la Comunidad Económica Europea, sino también el establecimiento de relaciones con Israel sin poner en peligro la tradicional amistad hispano-árabe. La defensa de los derechos nacionales palestinos ha permitido a España jugar un papel activo tanto en el proceso de paz como en el espacio euromediterráneo como puente de comunicación entre la Unión Europea y el mundo árabe.

\section{Palabras Clave: política exterior española; Oriente Medio; Israel; Palestina; conflicto árabe-israelí.}

\section{Spain, Israel and Palestine: Agreements and Disagreements}

ABSTRACT: Spanish foreign policy towards the Middle East has been conditioned by the Arab-Israeli conflict. During the Franco regime, the so-called "substitution policies" were prioritized. These policies were based on strengthening Spanish relations with Latin America and the Arab countries in a bid

* Este artículo es resultado del Proyecto de Investigación I+D «Resiliencia del autoritarismo, choque de islamismos e intensificación del sectarismo en Oriente Medio y el Magreb» (CSO2017-86091-P), financiado por el Ministerio de Economía, Industria y Competitividad (MINECO).

${ }^{1}$ ORCID iD: https://orcid.org/0000-0001-6454-8460.

Copyright: (C) 2019 CSIC. Este es un artículo de acceso abierto distribuido bajo los términos de una licencia de uso y distribución Creative Commons Reconocimiento 4.0 Internacional (CC-BY 4.0) 
to compensate for the international isolation imposed after the Second World War. Later, Spain had to face important challenges during its democratic transition, not only in the universalization of its diplomatic relations and its integration in the European Economic Community, but also the establishment of relations with Israel without compromising the Spanish-Arab friendship. Spanish support for Palestinian national rights opened the door for Spain to play an active role both in the peace process and in the Euro-Mediterranean area, as a bridge between the European Union and the Arab world.

KeY WORds: Spanish foreign policy; Middle East; Israel; Palestine; Arab-Israeli conflict.

CÓMO CITAR ESTE ARTÍCULO/CITATION: Álvarez-Ossorio Alvariño, Ignacio, «España, Israel y Palestina: encuentros y desencuentros», Hispania, 79/261 (Madrid, 2019): 221-248. https://doi.org/10.3989/hispania.2019.008.

\section{LA ETAPA FRANQUISTA (1939-1975)}

España es, en la actualidad, una potencia media en la escena internacional, pero no siempre ha sido así. Tras la Segunda Guerra Mundial, el régimen franquista quedó aislado debido a su proximidad a las potencias del Eje como deja claro la resolución 39 (1) de 1946 de la Asamblea General de la ONU:

Recomienda que se excluya al Gobierno español de Franco como miembro de los organismos internacionales establecidos por la ONU o que tengan nexos con ellos, y de la participación en conferencias u otras actividades que puedan ser emprendidas por la ONU o por estos organismos, hasta que se instaure en España un Gobierno nuevo y aceptable [...]. Recomienda que, si dentro de un tiempo razonable, no se ha establecido un gobierno cuya autoridad emane del consentimiento de los gobernados, que se comprometa a respetar la libertad de palabra, de culto y de reunión, y esté dispuesto a efectuar prontamente elecciones en que el pueblo español, libre de intimidación y violencia y sin tener en cuenta los partidos, pueda expresar su voluntad, el Consejo de Seguridad estudie las medidas necesarias que han de tomarse para remediar la situación.

Al haber sido excluida de las Naciones Unidas, España no participa en la votación del Plan de Partición de Palestina el 29 de noviembre de $1947^{2}$. No

\footnotetext{
2 No obstante, el diplomático republicano Pablo de Azcárate, repudiado por el régimen franquista, jugó un papel destacado en el seno de la Comisión de Palestina, un organismo creado por la resolución 181 (1947) de la Asamblea General con el objeto de «preparar y llevar a cabo la puesta en práctica» de dicho plan. Tras la creación de Israel en 1948, Azcárate fue comisario municipal provisional de Jerusalén y, entre 1949 y 1952, secretario principal de la Comisión para la Conciliación de Palestina, RAMOS TOLOSA, 2014: 189-213.
} 
obstante, el régimen franquista se identifica desde un primer momento con las posiciones árabes, entre otras razones porque confiaba en que dichos países secundasen en un futuro su incorporación a la ONU. Por otra parte, las afinidades socialistas de los líderes del movimiento sionista también despertaban fuertes suspicacias en el seno del régimen ${ }^{3}$. El asesinato del cónsul adjunto en Jerusalén Manuel Allendesalazar el 5 de enero de 1948 en la voladura del Hotel Semiramis por la fuerza paramilitar judía Haganah no contribuyó a mejorar la situación.

Tras la declaración de independencia de Israel, las autoridades sionistas se sumaron activamente a la campaña para mantener el aislamiento internacional del régimen franquista. Cuando el 11 de mayo de 1949 la Asamblea General de la ONU debatió la denominada «cuestión española», el embajador israelí Abba Eban afirmó: «Para nosotros, el punto central e inevitable es la asociación de este régimen con la alianza nazi-fascista que corroyó los cimientos morales de la vida civilizada e inflingió a la raza humana su más terrible y devastador castigo».

A partir de 1945, las dos principales prioridades de Franco fueron el mantenimiento del régimen y la ruptura del aislamiento internacional del que era objeto. Con el propósito de ganar respaldos internacionales, el ministro de Asuntos Exteriores Alberto Martín Artajo (1945-1957) puso en marcha diversas «políticas de sustitución», basadas en un acercamiento tanto a América Latina como al mundo árabe (y, en especial, a los regímenes monárquicos conservadores de Jordania, Arabia Saudí, Egipto, Iraq y Libia) ${ }^{4}$. En un primer momento, tampoco se escatimaron esfuerzos para establecer plenas relaciones diplomáticas con Israel, ya que se interpretaba que este movimiento allanaría el camino para una rehabilitación por parte de Estados Unidos y del resto de potencias occidentales. Fueron consideraciones de índole geopolítica las que llevaron al régimen franquista a tratar de aproximarse a Israel para, así, «obtener legitimidad moral, con cuyo auxilio confiaba desbaratar el boicot internacional que se le había impuesto y apresurar un acuerdo con Washington $»^{5}$.

Un paso imprescindible para ello, como señala Isidro González García, era «lavar la cara del régimen y presentar una cara distinta a la que se le atribuía, especialmente la más nociva, como era la pasada vinculación a los regímenes fascista y nazi [...]. Uno de los principales objetivos fue durante este tiempo que el Estado de Israel reconociese al régimen de Franco; la baza que se jugaba era la salvación por parte del mismo de miles de judíos de las atrocidades nazis» ${ }^{6}$. Con este objetivo, la dictadura franquista trató de difundir una nueva

\footnotetext{
3 MORÁN, 1980: 177.

${ }^{4}$ MORÁN, 1980:172.

5 REIN, 1996: 14.

${ }^{6}$ GONZÁLEZ GARCÍA, 2001: 25.
}

Hispania, 2019, vol. LXXIX, nº 261, enero-abril, págs. 221-248, ISSN: 0018-2141, e-ISSN: 1988-8368 https://doi.org/10.3989/hispania.2019.008 
narrativa centrada en la neutralidad española durante la Segunda Guerra Mundial y su activa participación en la salvación de miles de judíos sefardíes del Holocausto $^{7}$. Un buen ejemplo lo ofrece el documento España y los judios, editado en inglés y francés por la Oficina de Información Diplomática en 1949, que señala:

España, imbuida de su espíritu cristiano y universal de amor a todas las razas de la tierra contribuyó al rescate de judíos y procedió más por intereses espirituales que por razones políticas o simplemente jurídicas. La ayuda de nuestro gobierno no sólo se extendió a los sefarditas dispersos por los continentes, sino también a todos los judíos cuando se presentó la ocasión, sin considerar su nacionalidad o el lugar en que se hallaban ${ }^{8}$.

Entre 30.000 y 35.000 judíos sefardíes fueron salvados de la deportación y el exterminio gracias a la implicación de las autoridades diplomáticas y consulares españolas, aunque el régimen duplicó la cifra con fines propagandísticos ${ }^{9}$. En la mayor parte de los casos se les otorgaron visados de tránsito para que pudieran emigrar a América y el Norte de África ${ }^{10}$. En su libro Más allá del deber. La respuesta humanitaria del Servicio Exterior frente al Holocausto, José Antonio Lisbona deja claro que la dictadura «intensificó acciones de relaciones públicas encaminadas a presentarse en el ruedo internacional como potencia protectora de «todos» los sefardíes e incluso de «todos» los judíos, no solo de los de nacionalidad española», lo que para el autor se trata de una evidente «tergiversación $»^{11}$, puesto que que los diplomáticos y miembros del Servicio Exterior actuaron de manera individual poniendo en riesgo sus propias vidas. De esta misma opinión es Raanan Rein, quien advierte que «los esfuerzos desarrollados para rescatar judíos, tanto en la Segunda Guerra Mundial

${ }^{7}$ BAER, 2001: 504.

8 OFICINA DE INFORMACIÓN DIPLOMÁTICA, 1949: 15.

9 LISBONA, 2015: 40.

${ }^{10}$ El ministro de Asuntos Exteriores Francisco Gómez-Jordana (1942-1944) dejó claro que ni Franco ni el régimen deseaban que dichos judíos sefardíes se establecieran en la península ibérica: «Desde hace muchos meses está planteado el problema de los sefarditas de Oriente y en general de toda la Europa ocupada por el Eje. Estos sefarditas, con nacionalidad española indudable y con documentación completa que lo acredita, pidieron venir a España, encontrándose algunos en campos de concentración en Alemania. El problema tiene gravedad por cuanto no conviene en absoluto a nuestro país que, aprovechando las circunstancias de la guerra actual, se nos llene España de judíos y, por otra parte, tampoco podemos negarles la protección a que tienen derecho por su nacionalidad y, aunque quisiéramos hacerlo, sería siempre una torpeza política por la repercusión que tendría en el extranjero, campañas que suscitarían contra nosotros, acusaciones a que daría lugar suponiéndonos una política antisemita copiada de la de Alemania», Carta del ministro de Asuntos Exteriores Francisco Gómez-Jordana al Alto Comisario en Marruecos Luis Orgaz del 30 de diciembre de 1943, citado en LISBONA, 2015: 45.

${ }^{11}$ LISBONA, 2015: 47. 
como en el periodo de posguerra en los países árabes, fueron a menudo resultado de la iniciativa de diplomáticos españoles en varios lugares y no el resultado de una política clara fijada por el Palacio de Santa Cruz, sede del Ministerio de Asuntos Exteriores, ni del Palacio de El Pardo, residencia del generalísimo Franco» ${ }^{12}$.

No obstante, el gobierno israelí rechazó por activa y por pasiva dichos intentos de aproximación. De hecho, el ministro de Asuntos Exteriores Moshe Sharett (1948-1956) «adoptó una posición hostil hacia el régimen del dictador Francisco Franco no por el recuerdo de la expulsión de los judíos, ni de las persecuciones de la Inquisición [...], sino por las evidentes muestras de simpatía del franquismo hacia el régimen nazi durante la Segunda Guerra Mundial; un comprensible compromiso personal e ideológico antifranquista, contraído por muchos altos funcionarios del Ministerio de Relaciones Exteriores y la élite gubernamental, todavía en los días de la Guerra Civil; razones pragmáticas de política exterior, consideraciones respecto a la opinión pública internacional o referentes a los diversos partidos políticos israelíes $\rangle^{13}$.

Para tratar de sortear el aislamiento internacional, España puso en marcha las «políticas de sustitución» que tenían como eje central la aproximación a los países árabes. Esta política fue facilitada por diversas cuestiones, entre ellas la empatía de Franco y los militares africanistas hacia el mundo árabe desde la época del Protectorado marroquí, la tendencia árabe de identificar España con al-Andalus, la falta de ambiciones coloniales españolas en Oriente Medio, los sentimientos francófobos y anglófobos del franquismo y la presencia de militares tanto en los gobiernos árabes como en España ${ }^{14}$. Esta primera aproximación fue esencialmente al «mundo árabe conservador y dinástico y es anterior a la aparición de los denominados socialismos árabes del Egipto de Nasser o la Siria del Baath $\rangle^{15}$. De hecho, fue el rey Abdallah de Jordania el primer mandatario internacional en visitar España el 5 de septiembre de 1949 y su reunión con Franco se centró en la mediación jordana en la rehabilitación del régimen franquista y la internacionalización de los Santos Lugares de Jerusalén ${ }^{16}$. En los años siguientes, diversos monarcas árabes realizaron visitas oficiales a España: Husayn de Jordania en 1955, 1967 y 1972, Faysal II de Iraq en 1952 y 1956, Idris I de Libia en 1953, Muhammad V y Hasan II de Marruecos en 1956 y 1963 respectivamente y Saud y Faysal de Arabia Saudí en 1957 y 1966 respectivamente. En la primera década de los cincuenta, las monarquías árabes mediaron ante Estados Unidos para poner fin al aislamiento internacional de

\footnotetext{
12 REIN, 2006: 22.

13 REIN, 1996: 13.

14 ALGORA, 1995: 268.

15 MORÁN, 1980: 173-174.

16 PÉREZ MATEO, 2007: 22-44.
}

Hispania, 2019, vol. LXXIX, nº 261, enero-abril, págs. 221-248, ISSN: 0018-2141, e-ISSN: 1988-8368 https://doi.org/10.3989/hispania.2019.008 
España, abogaron por su incorporación a la ONU y proveyeron de petróleo al régimen franquista, todo ello a cambio del mantenimiento de las posiciones anti-israelíes por parte de España, su apoyo a la protección de los Santos Lugares y su intermediación ante los países latinoamericanos ${ }^{17}$.

La creciente hostilidad entre los EEUU y la URSS y el inicio de la Guerra Fría favorecieron la rehabilitación internacional del régimen franquista. El 4 de noviembre de 1950, la resolución 39 del Consejo de Seguridad fue revocada y el 23 de septiembre de 1953 se firmaron los Acuerdos de Madrid por los cuales se establecieron cuatro bases militares norteamericanas en territorio español. El combate contra el comunismo se convertía en una prioridad absoluta para la Administración de Eisenhower, que no dudó en allanar el camino para la normalización plena de relaciones con Franco debido al interés geoestratégico de España.

Este hecho provocó un cambio de actitud israelí, que optó por enviar emisarios al régimen franquista para tratar de acercar posiciones. En 1953, Moisés Galili, representante oficioso israelí, transmite al Ministerio de Asuntos Exteriores español: «El Gobierno de Israel quiere utilizar a España como potencia que en calidad de árbitro negocie la paz entre Israel y los demás países árabes sin que esto entrañe en sí un acuerdo bilateral previo ni posterior entre España e Israel y sin menoscabo de la política hispanoárabe del Gobierno español $\rangle^{18}$. El objetivo sería que España aprovechase sus buenas relaciones con el mundo árabe para mediar entre las partes para resolver el conflicto y alcanzar una solución sobre la cuestión de fronteras, el problema de los refugiados y la internacionalización de Jerusalén ${ }^{19}$.

Tras años de desencuentro comienza a fraguarse un cambio de actitud por parte del Ministerio de Asuntos Exteriores israelí tras la salida de Sharett y la llegada de Golda Meir (1956-1966), a través del «grupo de presión profranquista que deseaba rehabilitar a la dictadura española ante la opinión pública israelí y promover el establecimiento de relaciones hispano-israelíes ${ }^{20}$. No obstante, esta apuesta llega demasiado tarde, ya que España ya había conseguido normalizar sus relaciones con los países occidentales y, además, temía que el reconocimiento de Israel pasase factura a las relaciones con el mundo árabe, sobre todo tras el nombramiento de Fernando María Castiella como nuevo ministro de Asuntos Exteriores (1957-1969) ${ }^{21}$.

17 EIROA SANFRANCISCO, 2013: 29-30.

18 GONZÁLEZ GARCÍA, 2001: 124.

19 Tal y como reconocería el ministro de Asuntos Exteriores Martín Artajo al secretario de la Liga Árabe Ahmad Shukeyry en una entrevista desarrollada en Madrid el 14 de diciembre de 1953, GONZÁLEZ GARCÍA, 2001: 121-122.

${ }^{20}$ REIN, 1996: 15.

${ }^{21}$ SETTON, 2016: 54.

Hispania, 2019, vol. LXXIX, nº 261, enero-abril, págs. 221-248, ISSN: 0018-2141, e-ISSN: 1988-8368 https://doi.org/10.3989/hispania.2019.008 
El régimen franquista tomó buena nota del boicot israelí que sufrió durante su particular travesía del desierto que se prolongó desde el final de la Segunda Guerra Mundial hasta su entrada en la ONU. Como señala Samuel Hadas, primer embajador isaelí en España (1986-1987): «El "legado israelí" de la diplomacia del régimen franquista a la democracia española fue una política que fue evolucionando desde la búsqueda de un acercamiento a Israel apenas nacido el Estado judío en 1948 hacia la hostilidad y, finalmente, el rechazo total ${{ }^{22}}^{2}$. En opinión de Shlomo Ben-Ami, que le reemplazó en el cargo (1987-1991), «la adopción de una inexorable actitud antiisraelí era, a fin de cuentas, un precio bastante bajo que España podía permitirse para reforzar su amistad con el mundo árabe» ${ }^{23}$.

Tras su incorporación a la ONU en 1955, España rechazó varias tentativas israelíes de establecer relaciones diplomáticas ${ }^{24}$, entre otras razones porque este paso sería contemplado como «un bofetón a los países árabes» ${ }^{25}$. El acceso al poder de las fuerzas progresistas en el mundo árabe (sobre todo en Egipto, Iraq y Siria) no suscitó un cambio de esta tendencia, sino más bien su acentuación. Durante la guerra del Sinaí en 1956, el régimen franquista «mostró simpatía hacia Egipto, una posición que le permitió aparecer como un amigo de los árabes en contraste con el «imperialismo» de Gran Bretaña, Francia e Israel [...]. La prensa de Madrid (Arriba, Madrid, Pueblo y Ya) acogió la nacionalización del canal con entusiasmo» ${ }^{26}$.

Con la Guerra Fría como telón de fondo, Franco consideró imprescindible que España se alineara con EEUU para frenar la penetración soviética en el Mediterráneo. No obstante, la distensión de los años sesenta llevó a replantear esta posición. A partir de entonces, España puso en escena «una política más ambiciosa y diversificada en sus canales de acción, como las pulsiones neutralistas o un discurso desarrollista de cierta empatía con los problemas del Tercer Mundo ${ }^{27}$. En todo caso, cabe subrayar que esta retórica en torno a la amistad hispano-árabe no dio los resultados esperados. El régimen franquista se vio obligado a hacer equilibrismos para no indisponerse con ninguno de los dos bandos en los que se dividió el mundo árabe durante su particular Guerra Fría: las monarquías conservadoras prooccidentales y los regímenes revolucionarios nacionalistas. En este sentido, la política de Franco fue ambivalente, ya que «vació de contenido las relaciones bilaterales con el objetivo de no perder a ninguno de los dos grupos, siguiendo su costumbre de conservar a todas la par-

\footnotetext{
${ }^{22}$ HADAS, 2010: 13.

23 BEN AMI, 1980: 116.

${ }^{24}$ GONZÁLEZ GARCÍA, 2001: 113-200.

${ }^{25}$ MARQUINA, 1996: 553.

${ }^{26}$ REIN, 2006: 23.

27 NEILA, 2011: 388.
}

Hispania, 2019, vol. LXXIX, nº 261, enero-abril, págs. 221-248, ISSN: 0018-2141, e-ISSN: 1988-8368 https://doi.org/10.3989/hispania.2019.008 
tes para, llegado el momento, decantarse por la más conveniente a sus necesidades $\rangle^{28}$.

Este posicionamiento anti-israelí no impidió que España siguiese intercediendo, como ya había hecho durante la Segunda Guerra Mundial, a favor de los judíos sefardíes. Tras la independencia de Marruecos «el régimen de Franco prestó secretamente una ayuda de incalculable valor para facilitar la salida de decenas de miles de judíos marroquíes, que en su mayoría emigraron a Israel $\rangle^{29}$. Efectivamente, entre 1961 y 1964 unos 97.000 judíos sefardíes marroquíes abandonaron Marruecos en el curso de la Operación Yakhin, con la colaboración del régimen franquista que permitió que el territorio español fuera empleado como zona de tránsito en su camino hacia Israel, aunque parte de ellos optaron por establecerse en Francia, Estados Unidos y Canadá3 ${ }^{30}$

En el marco de la guerra de los Seis Días (1967), España volvió a ofrecer sus servicios para proteger a la minoría judía en Egipto. La embajada española en El Cairo fue aleccionada para ofrecer documentos de viaje y costear los billetes para todos aquellos judíos sefardíes que desearan abandonar el país, y el embajador español Ángel Sagaz se comprometió ante las autoridades egipcias a que los 1.500 judíos que se beneficiaron de la mediación española no se establecerían en Israel. El historiador israelí Raanan Rein interpreta que esta política no fue altruista, sino que estaba orientada a «crear una imagen liberal de la dictadura y fortalecer los lazos con los países occidentales $\rangle^{31}$, aunque debe recordarse que la España franquista ya había sido años antes rehabilitada por la comunidad internacional.

Tras la guerra de los Seis Días, España condenó con rotundidad la ocupación israelí del desierto del Sinaí, los Altos del Golán, Cisjordania, Jerusalén Este y la Franja de Gaza. El régimen franquista exigió la retirada israelí de los territorios árabes recientemente ocupados y supeditó un eventual acercamiento diplomático hispano-israelí a dos condiciones: la mejora de relaciones entre Israel y el entorno árabe y la internacionalización de Jerusalén, aludiendo a la responsabilidad histórica española en la protección de los Santos Lugares $^{32}$.

La posición española no se modificó a pesar de ciertos contactos de carácter secreto, como el desarrollado en 1970 entre el ministro de Asuntos Exteriores Gregorio López-Bravo (1969-1973) y su homólogo israelí Abba Eban (19661974). A principios de 1973, Israel rechazó la oferta española de abrir una oficina comercial en Madrid, ya que «la postura de la diplomacia israelí era «todo

\footnotetext{
${ }^{28}$ EIROA SANFRANCISCO, 2013: 46.

29 HADAS, 2010: 12.

${ }^{30}$ REIN, 2006: 28.

31 REIN, 2006: 22.

32 ALGORA, 2003: 42.
}

Hispania, 2019, vol. LXXIX, nº 261, enero-abril, págs. 221-248, ISSN: 0018-2141, e-ISSN: 1988-8368 
o nada», es decir, relaciones diplomáticas plenas o nada» ${ }^{33}$. Tras la guerra de Yom Kippur en 1973, en el curso de la cual España impidió a EEUU emplear sus bases militares en territorio español para enviar armamento a Israel, el Ministerio de Asuntos Exteriores español envió delegaciones a Irak, Kuwait y Arabia Saudí para garantizar que el petróleo siguiese fluyendo hacia España. El 22 de noviembre de 1974, España se posicionó a favor de los derechos nacionales palestinos al votar a favor de las resoluciones de la Asamblea General números 3.236 (sobre el derecho a la autodeterminación del pueblo palestino) y 3.237 (que reconocía a la Organización para la Liberación de Palestina como su representante legítimo y le otorgaba estatuto de observador en la $\mathrm{ONU})^{34}$.

\section{LAS PRESIDENCIAS de SuÁrez y CALVo-Sotelo (1977-1982)}

En los últimos años del periodo franquista se dio un efecto embudo por el cual se aplazaron numerosas decisiones relevantes, entre ellas la descolonización del Sáhara español, debido al inminente colapso del régimen. Tras la muerte de Franco, las tareas pendientes eran numerosas: la universalización de relaciones diplomáticas, la homologación de la política multilateral y la europeización de las opciones estratégicas españolas y, sobre todo, la incorporación a la Comunidad Económica Europea ${ }^{35}$.

Durante el periodo de transición se favoreció la inserción española en el sistema internacional, dado que «el objetivo prioritario de los primeros gobiernos de la transición fue la superación de la herencia exterior del franquismo y la normalización de las relaciones internacionales de España, con el objetivo de avanzar en la universalización de las relaciones diplomáticas y lograr la homologación de España con el entorno europeo ${ }^{36}$. A pesar del establecimiento de relaciones dipomáticas con la Unión Soviética y el bloque comunista en 1977, la política exterior hacia Oriente Medio mantuvo cierta inercia debido a las posibles represalias por parte de los países árabes, el temor a la reacción de los sectores ultraderechistas, la subida de los precios del petróleo, el escaso ascendente de la comunidad judía española y la necesidad de conservar las buenas relaciones con el mundo árabe ${ }^{37}$.

El establecimiento de relaciones con Israel, contemplado por el ministro de Asuntos Exteriores José María de Areilza (1975-1976) durante el Gobierno de Arias Navarro, quedó en suspenso por sus posibles efectos negativos en las

\footnotetext{
33 HADAS, 2010: 13.

${ }^{34}$ BARREÑADA, 2018: 135.

35 VIÑAS, 2006: 108.

36 NEILA, 2011: 437.

37 REIN, 1996: 322-323.
}

Hispania, 2019, vol. LXXIX, n 261, enero-abril, págs. 221-248, ISSN: 0018-2141, e-ISSN: 1988-8368 https://doi.org/10.3989/hispania.2019.008 
relaciones con el mundo árabe. Tras la victoria electoral de la Unión de Centro Democrático (UCD), la política exterior del presidente Adolfo Suárez «es en cierto modo continuista de la época del tardo franquismo, es decir se mantiene la tesis de la devolución a los palestinos de los territorios ocupados, al tiempo que se propugna una seguridad para el Estado de Israel como país con una fronteras fijas y seguras $»\rangle^{38}$.

En esta primera etapa de la transición, las presiones sobre el gobierno español se intensificaron por medio de diferentes actores, entre ellos la Comisión Europea, la Administración norteamericana, el lobby israelí en Estados Unidos y representantes oficiosos israelíes ${ }^{39}$. No obstante, también existió un fuerte contrapeso «por medio de presiones externas (Liga Árabe, Consejo de Embajadores Árabes, radicales: Siria y Libia, moderados: Arabia Saudí y Jordania, terrorismo) o por medio de presiones internas (partidos políticos, medios de comunicación, carrera diplomática, etc.), que intentan que España retrase o abandone la normalización diplomática» ${ }^{40}$.

El presidente Adolfo Suárez, partidario del neutralismo, impulsó las relaciones hispano-palestinas para adaptarlas a la nueva coyuntura internacional, marcada por el agravamiento de la crisis energética mundial y el reconocimiento internacional de la Organización para la Liberación de Palestina, OLP. El ministro de Asuntos Exteriores Marcelino Oreja (1976-1980) se mostró favorable a mantener una política continuista en su comparecencia ante el Senado del 9 de marzo de 1978, al posicionarse a favor del derecho de existencia de todos los Estados dentro de sus fronteras seguras y reconocidas, la retirada de Israel de los territorios ocupados y el reconocimiento de los derechos nacionales del pueblo palestino de acuerdo con lo establecido por las resoluciones de la ONU. En su gira por varios países árabes, Oreja incidió en que España no establecería plenas relaciones diplomáticas con Israel hasta que se retirase de los territorios ocupados y reconociera los derechos del pueblo palestino ${ }^{41}$.

Suárez fue el primer mandatario europeo en recibir, el 13 de septiembre de 1979, al presidente de la OLP Yaser Arafat, lo que generó numerosas protestas por parte de las comunidades judías españolas. En su intervención ante la Asamblea General de la ONU, el 22 de septiembre de 1980, el ministro de Asuntos Exteriores José Pedro Pérez-Llorca (1980-1982) abogó por el reconocimiento mútuo y la negociación entre Israel y la OLP:

Para llegar a esa paz, el Gobierno español entiende que es es necesario idear un nuevo esquema político, cuya pieza central ha de estar en el mutuo reconocimiento

\footnotetext{
${ }^{38}$ GONZÁLEZ GARCÍA, 2001: 261.

39 HADAS, 2010: 15.

${ }^{40}$ LISBONA, 2006: 124.

${ }^{41}$ REIN, 1996: 326.
}

Hispania, 2019, vol. LXXIX, nº 261, enero-abril, págs. 221-248, ISSN: 0018-2141, e-ISSN: 1988-8368 
de Israel y la OLP como partes interesadas en el conflicto y en la necesidad de que ambas abandonen sus objetivos maximalistas y se avengan a negociar. No se puede pretender borrar a Israel y a su pueblo del mapa de Oriente Medio, porque nadie le puede negar su derecho a vivir en paz, dentro de fronteras que han de ser seguras y reconocidas, pero que no pueden basarse en la anexión de los territorios ocupados por la fuerza.

Aunque a menudo se ha argumentado que el factor securitario influyó en esta decisión ${ }^{42}$, lo cierto es que el temor a sufrir atentados terroristas no parece haber sido un factor determinante a la hora de explicar dicha apuesta. Probablemente jugara un papel más relevante la necesidad de garantizar el acceso al petróleo árabe en el periodo especialmente convulso que siguió a la guerra de Yom Kippur. La buena relación del rey Juan Carlos I con las monarquías petrolíferas del golfo Pérsico contribuyó decisivamente a garantizar el acceso al crudo en un momento especialmente delicado. Tampoco la llegada al gobierno del Likud, su política colonizadora en los Territorios Ocupados y la invasión israelí del sur del Líbano crearon las condiciones idóneas para dicha aproximación hispano-israelí.

Durante la presidencia de Calvo-Sotelo se registró un punto de inflexión, ya que se planteó la posibilidad de acelerar el establecimiento de relaciones con Israel al considerarse un anacronismo la ausencia de ellas. En 1981, PérezLlorca se entrevistó en secreto en Nueva York con el primer ministro israelí Isaac Shamir, aunque la invasión israelí de Líbano de 1982 y las masacres de Sabra y Shatila cortaron de raíz dicha posibilidad ${ }^{43}$.

\section{LA PRESIDENCIA de GoNZÁLEZ (1982-1996)}

Tras la victoria electoral del Partido Socialista Obrero Español (PSOE) en las elecciones legislativas de 1982, el presidente Felipe González imprimió un profundo giro en la política exterior española con la integración plena en la Organización del Atlántico Norte y la Comunidad Económica Europea. También desarrolló, por primera vez, una verdadera política exterior hacia el Mediterráneo, que «se convirtió en uno de los espacios geográficos en los que la diplomacia española ha mostrado mayor ambición, con el doble objetivo de fortalecer su posición como potencia regional y reforzar la defensa de sus intereses en seguridad en el Magreb» ${ }^{44}$.

En el seno del PSOE existían diferentes corrientes, pero al final se impuso la europeísta y atlantista, lo que en ningún caso implicó que se abandonara la vocación neutralista y la simpatía hacia las causas tercermundistas, como

\footnotetext{
42 PORTERO, 2008: 184. REIN, 1996: 325.

43 HADAS, 2010: 17.

${ }^{44}$ HERNANDO DE LARRAMENDI y MAÑÉ ESTRADA, 2009: 9.
} 
quedó patente en el posicionamiento ante la cuestión palestina. El presidente Felipe González remarcó su apoyo a una solución justa y duradera del conflicto árabe-israelí en el marco de las resoluciones de la ONU y del Derecho Internacional, aunque sus estrechas relaciones con el Partido Laborista, también miembro de la Internacional Socialista, serían de gran utilidad para allanar el establecimiento de relaciones diplomáticas ${ }^{45}$.

Poco antes de ser designado ministro de Asuntos Exteriores (1982-1985), Fernando Morán incidía en que el establecimiento de relaciones con Israel debía supeditarse a la retirada israelí de los territorios ocupados. En una entrevista, Morán afirmaría: «España no puede premiar la anexión de territorios por la fuerza; cabría un establecimiento de relaciones dejando muy claro que no se considera zona israelí los territorios ocupados ni tampoco la ciudad de Jerusalén en su totalidad $»^{46}$. En consecuencia con lo anterior, Morán abogaba por «mantener una relación institucional con la OLP, no dejarse arrastrar por ningún maniqueísmo, evitar toda hostilidad hacia el pueblo israelí y planear nuestra política resistiendo presiones y conveniencias del momento», ya que «los grupos de presión de los regímenes políticos y económicos de las superpotencias no deben prevalecer sobre los derechos de los pueblos $\rangle^{47}$.

Para tratar de ganar respaldos a las tesis israelíes en el seno de la escena española, el ministro de Asuntos Exteriores israelí Isaac Shamir (1980-1986) envió a Samuel Hadas como representante ante la Organización Mundial de Turismo con sede en Madrid, quien actuó desde 1980 como embajador «oficioso» hasta el establecimiento pleno de relaciones. Esta decisión no fue bien recibida por las autoridades españolas ya que, como recuerda el propio Hada: «Durante los primeros años tropezaría con la incomprensión y el "malestar" del gobierno español por mi gestión e incluso con actitudes hostiles del gobierno y de su diplomacia, que incluyeron trabas burocráticas a mi labor» ${ }^{48}$.

El ministro de Asuntos Exteriores Francisco Fernández Ordoñez (1985-1992) aceleró el proceso de normalización que coincidió con el ingreso español en la CEE. El 17 de enero de 1986 España e Israel establecieron plenas relaciones diplomáticas por medio de la Declaración de La Haya, «de conformidad con el principio de universalidad de relaciones entre Estados y teniendo en cuenta los antiguos y profundos vínculos que unen al pueblo español y al pueblo judío». Tanto Felipe González como Simon Peres inscribieron la normalización de las relaciones como la reparación de «un error histórico cometido con la expulsión de los judíos de España y la interrupción del fructífero lazo entre los dos pueblos mediterráneos», argumento cuestionable ya que «si España debía cancelar una

\footnotetext{
45 AMADO CASTRO, 2014.

46 Entrevista en Pueblo, 2-2-1981, citado en GONZÁLEZ GARCÍA, 2001: 265.

${ }^{47}$ MORÁN, 1980: 184-185.

48 HADAS, 2010: 16.
} 
deuda moral o dilucidar un arreglo de cuentas histórico, no era con la entidad política denominada Estado de Israel, sino con el pueblo judío» ${ }^{49}$. En opinión de Miguel Ángel Moratinos y Bernardino León, estos dos acontecimientos permitieron a España «la superación del franquismo y, con ella, la de sus políticas, entre ellas las de la retórica y hueca "política árabe", así como la de superar la carencia de relaciones diplomáticas con Israel $\gg{ }^{50}$.

El Comunicado conjunto hispano-israelí apenas tenía 14 líneas a las que el gobierno español añadió una consensuada Declaración con motivo del establecimiento de relaciones con Israel, en la que subrayaba que esta normalización no sería a costa de los derechos palestinos y tampoco implicaría la revisión de las estrechas relaciones con el mundo árabe:

El Gobierno español reafirma la vigencia de la prohibición de recurrir a la amenaza o al uso de la fuerza que impide, en esencial, reconocer cualquier adquisición territorial que haya sido efectuada por dichos medios; en consecuencia, reitera el no reconocimiento por España de cualesquiera medidas dirigidas a anexionarse territorios árabes ocupados a partir de 1967, o a alterar unilateralmente la naturaleza o el status de la ciudad de Jerusalén, cuyo libre acceso debe estar siempre abierto para todos. En este contexto, España rechaza la política de construir asentamientos en los territorios ocupados y reclama su desmantelamiento como primer paso para la devolución de los territorios [...]. El Gobierno español considera que deben reconocerse y garantizarse los legítimos derechos y aspiraciones del pueblo palestino, singularmente el de autodeterminación. Simultáneamente, se debe garantizar el derecho a la existencia pacífica de todos los Estados de la región, dentro de fronteras seguras e internacionalmente reconocidas [...]. España expresa su convicción de que todas las partes implicadas deberían aceptar las Resoluciones pertinentes de la ONU, y especialmente las resoluciones 242 y 338 del Consejo de Seguridad, que deben constituir la base para la búsqueda de una solución pacífica, justa y duradera del conflicto árabe-israelí. Sobre esa base, y para llegar a esa solución, se hace precisa la apertura de un proceso negociador entre las partes interesadas, bajo auspicios internacionales apropiados, en el que participe la OLP, como representante del pueblo palestino. ${ }^{51}$

Un elemento clave de la Declaración de La Haya es que España empieza a perfilarse como mediador entre las partes al señalar: «España expresa su confianza de que, con su ingreso en la Comunidad Europea, puede contribuir más activamente a abrir la vía a una solución global, justa y duradera del conflicto, y se dispone a no ahorrar esfuerzos por este objetivo». Esta reivindicación quedaría confirmada años después en la Conferencia de Paz de Madrid de 1991.

49 REIN, 1996: 11-12.

50 MORATINOS y LEÓN, 2003: 107.

51 Extracto de la Declaración del Gobierno de España con motivo del Establecimiento de Relaciones con Israel (17/1/1986), tomado de GIMÉNEZ PIERNAS, 1986: 733-734. 
El reconocimiento de Israel permitió a España desempeñar el papel de mediador en el conflicto palestino-ísraelí. El diplomático Eudaldo Miralpeix, embajador de España en Israel (2003-2008), considera que fue precisamente esta normalización la que permitió a España asumir un mayor protagonismo en Oriente Medio y erigirse en intermediario entre las partes y plantear diferentes iniciativas de calado en el seno de la Unión Europea ${ }^{52}$. España asumió por primera vez la presidencia de la UE en enero de 1989, circunstancia que aprovechó para impulsar la Declaración de Madrid, que iba más allá de la Declaración de Venecia de 1980. En un contexto marcado por la irrupción de la Intifada y la proclamación del Estado palestino en Argel, el Consejo Europeo del 27 de junio de 1989 aprobó la Declaración de Madrid, que demandaba «el reconocimiento de los derechos legítimos del pueblo palestino, incluyendo su derecho a la autodeterminación con todo lo que ello implica» y la celebración de «una Conferencia Internacional de Paz bajo los auspicios de la ONU, foro apropiado para negociaciones directas entre las partes implicadas (incluida la OLP), con vistas a llegar a una solución global, justa y duradera». Además, dicha declaración se oponía frontalmente a las políticas de hechos consumados practicadas por Israel y a sus intentos de alterar de manera unilateral la situación de los Territorios Ocupados por medio de la colonización y la construcción de asentamientos.

Esta conferencia internacional no tardó en llegar. Entre el 30 de octubre y el 1 de noviembre de 1991, Madrid acogió una Conferencia de Paz de Oriente Medio patrocinada por EEUU y la URSS. Aunque dicha conferencia fue presentada como la culminación de la política exterior española, este evento no debería sobrevalorarse puesto que la CEE quedó relegada a un segundo plano en el subsiguiente proceso de paz limitándose a asumir su carga económica ${ }^{53}$. Además, debe tenerse en cuenta que las diferencias entre el marco negociador de la Conferencia de Madrid y las posiciones europeas, resumidas en la Declaraciones de Venecia y Madrid, eran notables. Por todo ello cabe concluir que, al no ser acompañadas de una estrategia efectiva, «la Declaración de Venecia y las estrategias subsiguientemente adoptadas por la CEE tuvieron un impacto escaso en el conflicto árabe-israelí o en el acercamiento entre Israel y la OLP $\rangle^{54}$.

La Conferencia de Madrid sirvió también para reforzar las relaciones hispano-israelíes. En diciembre de 1991, el presidente González realizó su primera visita oficial a Israel, mientras que el israelí Haim Herzog devolvió la visita el año siguiente. El 13 de septiembre de 1993 se firmó el Acuerdo de Oslo, por el cual se estableció un autogobierno transitorio en algunas porciones de Cisjordania y Gaza. Dos meses después, el rey Juan Carlos I realizó su primera visita oficial a Israel. El 24 de noviembre de 1994, el rey Juan Carlos recibió a Yaser

\footnotetext{
52 MIRALPEIX, 2006: 27.

53 KHADER, 2000: 503-520.

54 PETERS, 1999: 301.
}

Hispania, 2019, vol. LXXIX, nº 261, enero-abril, págs. 221-248, ISSN: 0018-2141, e-ISSN: 1988-8368 https://doi.org/10.3989/hispania.2019.008 
Arafat y a Isaac Rabin, que fueron galordanados con el Premio Príncipe de Asturias de Cooperación Internacional. En el jurado tomaron parte los exministros de Asuntos Exteriores Fernando Morán y Marcelino Oreja.

El fin de la Guerra Fría no sólo permitió la convocatoria de la Conferencia de Madrid, sino que también implicó la revisión de las relaciones entre las orillas del Norte y el Sur del Mediterráneo. La Conferencia de Barcelona, celebrada entre el 27-28 de noviembre de 1995, fue otro de los hitos de la nueva política exterior española. La Declaración de Barcelona incidió en la necesidad de convertir el mar Mediterráneo en un espacio de cooperación, paz, seguridad y bienestar a través de la cooperación política-securitaria, económica-financiera y socio-cultural, aunque no se puso el mismo énfasis en las tres dimensiones, ya que se priorizó el factor económico. También remarcó que la asociación euro-mediterránea no pretendía remplazar al Proceso de Oslo, «sino contribuir a su éxito» respaldando «la consecución de un acuerdo de paz justo, global y definitivo basado en las resoluciones del Consejo de Seguridad y en los principios recogidos en las cartas de invitación a la Conferencia de Paz de Madrid, incluido el principio "tierra por paz"». Aunque finalmente se optó por la complementariedad entre los Procesos de Oslo y Barcelona, lo cierto es que, desde un primer momento, se escucharon voces críticas que advirtieron de que un colapso de las negociaciones de paz árabe-israelíes podría incidir negativamente en la viabilidad del proyecto euro-mediterráneo. Pese a ello, no logró imponerse «la escuela de pensamiento que defendía la estricta separación entre ambas como la mejor fórmula para preservar el proyecto euro-mediterráneo de la inestabilidad de Oriente Medio ${ }^{55}$.

Dentro del nuevo marco de cooperación euro-mediterránea, la UE firmó varios tratados con los países de la ribera sureña. El 20 de noviembre de 1995 se firmó el acuerdo de asociación entre Israel y la UE que entró en vigor el 1 de junio de 2000. El acuerdo estableció una zona de libre cambio y afianzó la cooperación económica, la apertura de mercados, la libre circulación de capitales y un diálogo político regular. En mayo de 2004, en el marco de la Política de Vecindad Europea, se firmó el Plan de Acción entre la UE e Israel encaminado a «reforzar su interdependencia política y económica» y que «permitía la posibilidad de que Israel participase de manera progresiva en aspectos centrales de las políticas y programas de la UE, mejorar el grado y la intensidad de la cooperación política».

No cabe duda que la Conferencia de Madrid y el Proceso de Barcelona contribuyeron a proyectar a España y la afianzaron no sólo en el ámbito europeo, sino también en el espacio mediterráneo. Estos dos acontecimientos confirmaron la mayoría de edad de la política exterior española y sirvieron como trampolín para reforzar su imagen internacional.

\footnotetext{
${ }^{55}$ MORATINOS y LEÓN, 2003: 121.
} 


\section{La Presidencia de Aznar (1996-2004)}

La llegada al gobierno del Partido Popular (PP) en 1996 no implicó en un primer momento una revisión de la política exterior hacia la zona. El respaldo a la cuestión palestina continuó siendo una de las piedras angulares de la política española hacia Oriente Medio, tal y como prueba que entre 1994 y 2001 España fuera el sexto país donante de la Autoridad Palestina ${ }^{56}$. No obstante, el colapso del Proceso de Oslo y, de manera más clara, los atentados del 11 de septiembre de 2001 provocaron un punto de inflexión que se saldó con un acercamiento hacia las tesis israelíes y un distanciamiento de las posiciones palestinas.

Durante la primera legislatura de José María Aznar, el diplomático español Miguel Ángel Moratinos fue nombrado Enviado Especial de la UE ante el Proceso de Paz de Oriente Medio, el 28 de octubre de 1996. Este nombramiento, que puede interpretarse como un reconocimiento del papel desempeñado por España en el marco del proceso de paz, consagró a España como una de las voces europeas de más peso en el dossier palestino-israelí. La labor del Enviado Especial consistía en «establecer y mantener estrechos contactos con todas las partes del proceso de paz», «ofrecer los consejos y los buenos oficios de la UE cuando las partes lo requiriesen» y «contribuir cuando fuese solicitado a la aplicación de los acuerdos internacionales alcanzados entre las partes», todo ello sin chocar con la acción de los Estados miembros, con la Presidencia o el Consejo Europeo. Moratinos jugaría un importante papel en el Protocolo de Hebrón de 1996, el Memorándum Wye Plantation en 1999, las Negociaciones de Taba en 2001 y, de manera especial, en la creación del Cuarteto de Madrid en 2002 y el planteamiento de la Hoja de Ruta en $2003^{57}$. La UE pretendía que su posicionamiento ante la cuestión palestina sirviese como «test para la Política Exterior y de Seguridad Común y para la complementariedad entre europeos y norteamericanos $\gg{ }^{58}$.

Al mismo tiempo, el gobierno español puso un énfasis especial en la necesidad de velar por el cumplimiento de los derechos humanos. En las Líneas Generales de Política Exterior de junio de 2000, el Gobierno de Aznar consideraba los derechos humanos como «uno de los ejes fundamentales de la política exterior española» y el Plan Estratégico de Acción Exterior de septiembre de 2000 incidía en que España debería aspirar a ejercer un liderazgo en este aspecto $^{59}$. Siguiendo esta línea de acción, el ministro de Asuntos Exteriores Josep Piqué (2000-2002) afirmó ante la Comisión de Derechos Humanos de la

\footnotetext{
56 CARLAVILLA, 2003: 173-186.

57 MORATINOS, 2003: 257-268.

${ }_{58}$ MORATINOS, 1999.

59 FELIÚ, 2009: 27.
} 
ONU el 22 de marzo de 2001: «No puedo dejar de manifestar mi profunda preocupación por las graves violaciones de los derechos humanos que están teniendo lugar en los Territorios Ocupados por Israel». En esta misma intervención, Piqué denunció la política colonizadora de Israel, el uso excesivo de la fuerza y las ejecuciones sumarias.

La segunda legislatura marcó un cambio de posicionamiento del Gobierno de Aznar que coincidió con el fracaso de las negociaciones de Camp David y el estallido de la Intifada del Aqsa, que provocaron el colapso del Proceso de Oslo. A pesar de la crisis humanitaria provocada por la política de cierres y de castigos colectivos impuestos por las autoridades israelíes, el gobierno cargó las tintas sobre la Autoridad Palestina a la que acusó de ser excesivamente tolerante con la violencia. A partir de entonces, el gobierno español fue «más crítico con los dirigentes palestinos, denunciando su corrupción, actitud antidemocrática y responsabilidad en el ejercicio del terrorismo; y más comprensiva con Israel ${ }^{60}$. De esta manera se rompía el consenso bipartidista que, hasta aquel momento, habían mantenido los dos partidos mayoritarios españoles en torno a la cuestión palestina.

Tras los atentados del 11 de septiembre de 2001 el Gobierno de Aznar apostó por el reforzamiento del vínculo trasatlántico, lo que quedó de manifiesto en la tercera presidencia española de la UE durante el primer semestre de 2002. En 2003, Aznar respaldó la intervención norteamericana en Irak en la Cumbre de las Azores celebrada el 16 de marzo. Para tratar de contener las críticas a esta acción unilateral adoptada al margen del Consejo de Seguridad, la Declaración sobre el vínculo atlántico, firmada por Bush, Blair y Aznar, apoyó «un proceso de paz en Oriente Próximo en el que dos Estados - Israel y Palestina-, coexistan en paz, seguridad y libertad». Esta inclinación atlantista, que anteponía la relación con EEUU al fortalecimiento de la UE, implicó también una limitación del papel de España como interlocutor entre las dos orillas del Mediterráneo y, lo que es más importante, «una sensación de parálisis, cuando no de abandono o retroceso [en el Proceso de Barcelona]: la labor desarrollada se limita a gestionar lo ya existente, sin movilizar más medios humanos ni financieros, y no siempre de manera afortunada $\rangle^{61}$.

En los meses siguientes, el gobierno español secundó el enfoque de la administración norteamericana según el cual la reanudación del proceso de paz debería supeditarse al combate contra el terrorismo y la reforma de la Autoridad Palestina. La Hoja de Ruta planteada por el Cuarteto de Madrid (integrado por los EEUU, la UE, la ONU y Rusia) señaló que «sólo se alcanzará una solución al conflicto palestino-israelí a través del fin de la violencia y el terrorismo, cuando el pueblo palestino tenga una dirección que actúe con decisión contra

\footnotetext{
${ }^{60}$ PORTERO, 2008: 186-187.

${ }^{61}$ NÚÑEZ, 2005: 74.
}

Hispania, 2019, vol. LXXIX, nº 261, enero-abril, págs. 221-248, ISSN: 0018-2141, e-ISSN: 1988-8368 https://doi.org/10.3989/hispania.2019.008 
el terror y tenga voluntad de construir una democracia activa basada en la tolerancia y la libertad». La ministra española de Asuntos Exteriores Ana de Palacio (2002-2004) visitó en varias ocasiones la zona, presionando activamente al presidente Yaser Arafat para que aplicase la Hoja de Ruta y delegase en la figura del primer ministro parte de sus competencias.

En definitiva, las dos legislaturas de Aznar pueden resumirse de la siguiente manera: «El PP ha matizado el discurso tradicional proárabe de la derecha, mostrándose más crítico con los palestinos y más comprensivo con los intereses israelíes $\rangle^{62}$. La cuestión palestina quedó, además, encapsulada sin incidir negativamente en el desarrollo de las relaciones bilaterales hispano-israelíes ${ }^{63}$. Tras abandonar la Moncloa, el ex presidente Aznar endureció su discurso hacia los palestinos. En 2010 fue uno de los impulsores de Friends of Israel Initiative. En un artículo aparecido el 17 de junio de 2010 en el diario The Times, Aznar insistió en que «Israel es una parte fundamental de Occidente, que es lo que es gracias a sus raíces judeo-cristianas. Si el elemento judío de estas raíces se da la vuelta e Israel se pierde, entonces Occidente se pierde también ${ }^{64}$. También aludió a su valor geoestratégico como muro frente al islamismo: "Israel es nuestra primera línea de defensa en una región turbulenta que está constantemente en riesgo de caer en el caos; una región vital para nuestra seguridad energética, debido a nuestra dependencia del petróleo del Oriente Medio. Es nuestro frente en la lucha contra el extremismo».

\section{La PResidencia de Rodríguez Zapatero (2004-2011)}

Tras la victoria electoral del PSOE en las elecciones de 2004, el presidente José Luis Rodríguez Zapatero abogó por «una política exterior comprometida» y consideró la defensa de los derechos humanos como un componente fundamental de la política exterior ${ }^{65}$. La apuesta por el multilateralismo y el retorno a la legalidad internacional fueron dos de los principales ejes de este nuevo posicionamiento. El Gobierno de Zapatero también abanderó el retorno a las posiciones tradicionales ante la cuestión palestina, a la que consideró como «el núcleo del problema de la región y el gran cáncer de las relaciones internacionales». Para abordarlo, designó a Miguel Ángel Moratinos como ministro de

${ }^{62}$ CÓRDOBA, 2011: 168.

${ }^{63}$ La desconexión entre ambos asuntos es una constante reivindicación israelí, tal y como explicaba el embajador israelí en España Victor Harel: «Para cimentar nuestras relaciones, creo que es imprescindible que no hagamos a nuestras relaciones bilaterales rehenes del conflicto con los palestinos. Una desconexión — hasta donde sea posible - es imprescindible y contribuirá a la mejor «salud» de las relaciones bilaterales», HAREL, 2006: 42.

${ }^{64}$ AZNAR, 2010.

${ }^{65}$ FELIÚ, 2009: 27.

Hispania, 2019, vol. LXXIX, nº 261, enero-abril, págs. 221-248, ISSN: 0018-2141, e-ISSN: 1988-8368 https://doi.org/10.3989/hispania.2019.008 
Asuntos Exteriores y Cooperación (2004-2010), concediéndole un amplio margen de maniobra. Moratinos aportaba su dilatada experiencia, aunque el tiempo se encargaría de demostrar que no sería sufiente para resucitar el proceso de paz. Durante este periodo la cooperación internacional hacia los Territorios Ocupados aumentó de manera considerable llegando a superar los 100 millones de euros por año ${ }^{66}$.

La primera crisis que tuvo que afrontar el Gobierno de Rodríguez Zapatero fue la victoria en las elecciones legislativas del 25 de enero de 2006 de Hamas, organización incluida en la lista de organizaciones terroristas de la UE. Aunque en su primera comparecencia ante el Congreso de Diputados tras las elecciones palestinas, el responsable de la cartera de Exteriores destacó el hecho de que «las elecciones se desarrollaron con plena normalidad, fueron libres, hubo gran participación, transparencia y todas las garantías democráticas» $\mathrm{y}$, por lo tanto, «hay que respetar los resultados, tal y como han hecho la UE y el Cuarteto», pronto se alineó con la posición de la comunidad internacional exigiendo a Hamas que «cumpla con sus obligaciones internacionales, que cumpla con la aceptación de los acuerdos firmados y que renuncie a la violencia e inicie su nueva trayectoria reconociendo a Israel $»^{67}$. De tal manera, Moratinos se alineaba con las posiciones del Cuarteto, que unos días antes había exigido a Hamas que abandonase el terrorismo, reconociese a Israel y aceptase los Acuerdos de Oslo como marco para negociar una salida al conflicto ${ }^{68}$.

La operación «Lluvia de Verano» contra la Franja de Gaza en verano de 2006 marcó un punto de inflexión en la relación hispano-israelí. El presidente Rodríguez Zapatero expresó su «firme condena» al empleo «desproporcionado de la fuerza» y advirtió que «los silencios ante lo que hoy se vive en Oriente Medio pueden ser arrepentimientos mañana ${ }^{69}$. En su comparecencia ante la Comisión de Asuntos Exteriores del Congreso de Diputados del 19 de julio de ese año, Moratinos expresó su preocupación por la deriva de Gaza: «La destrucción de infraestructuras civiles, como la planta de electricidad de Gaza, y el aislamiento de la Franja, hacen temer que se produzca una grave crisis de carácter humanitario entre la ya muy castigada población palestina. El objetivo del Gobierno español es el de prevenir y resolver la crisis humanitaria en Gaza» ${ }^{70}$.

${ }^{66}$ THIEUX y NÚÑEZ, 2010: 1-66.

67 «Comparecencia del ministro de Asuntos Exteriores y de Cooperación, Miguel Ángel Moratinos Coyaubé, ante el Pleno del Congreso sobre cómo valora el Gobierno el resultado electoral de los comicios legislativos celebrados en Palestina el 25 de enero», Boletín Oficial del Congreso de Diputados, 147, 8 de febrero de 2006.

${ }_{68}$ ÁLVAREZ-OSSORIO, 2007: 192.

${ }^{69}$ El País, 20-7-2006.

70 «Comparecencia del ministro de Asuntos Exteriores y de Cooperación, Miguel Ángel Moratinos Coyaubé, ante la Comisión de Asuntos Exteriores del Congreso, para informar 
Ante esta nueva coyuntura, España apostó por rescatar viejas fórmulas que en el pasado habían dado buen resultado. El Gobierno de Rodríguez Zapatero concentró sus energías en plantear la celebración de una nueva conferencia de paz. En su intervención ante la Asamblea General de la ONU el 21 de septiembre de 2006, Moratinos manifestó:

Desde esta tribuna, hago un llamamiento a favor de una verdadera coalición por la paz. No se trata de redescubrir el Mediterráneo, sino de pasar del compromiso a la acción política y diplomática. Sí a la creación de un Estado palestino viable y pacífico. Sí a un apoyo decidido al presidente Mahmud Abbas. Sí al final de la violencia y el terror contra Israel. Sí a la reactivación del proceso de Madrid que comenzó hace 20 años. Sí al relanzamiento de las conversaciones entre Siria e Israel. Debemos decir sí al final de la tragedia. La única vía de solución posible es la acción política y diplomática, no la militar ${ }^{71}$.

Esta propuesta apenas obtuvo apoyos más allá de los de Francia, Bélgica e Italia. España tuvo que contentarse con la aprobación, en el curso del Consejo Europeo celebrado en Bruselas el 14 y el 15 de diciembre de 2006, de una Declaración sobre Oriente Medio que, además, reclamó el cumplimiento de la Hoja de Ruta:

Las partes deben adoptar pasos concretos e inmediatos para poner fin a todos los actos de violencia y todas las actividades que sean contrarias al derecho internacional, incluidas las actividades colonizadoras y la construcción de la barrera en el territorio palestino, que constituyen un obstáculo para la consecución de este objetivo. La UE no reconocerá ningún cambio en las fronteras previas a 1967 que no sea reconocido por ambas partes ${ }^{72}$.

Tras la operación «Plomo Fundido» contra la Franja de Gaza en diciembre de 2008, Rodríguez Zapatero recibió al presidente palestino Mahmud Abbas, muy cuestionado a nivel interno por su gestión de la crisis. En dicho encuentro, el presidente español condenó «la reacción desmedida» de Israel pero, a continuación, intentó que dicha crítica no deteriorase las relaciones bilaterales manifestando que «a los amigos hay que hablarles con sinceridad». Como en ocasiones pasadas, la inmovilidad diplomática se trató de compensar con la concesión de nuevas ayudas económicas para paliar la catastrófica situación humanitaria (en esta ocasión, cinco millones de euros para la UNRWA, Agencia de Naciones Unidas para los Refugiados en Oriente Medio).

Tras la segunda visita oficial de Rodríguez Zapatero a Israel en octubre de 2009, el gobierno español se mostró cada vez más contemporizador con el

sobre la posición española en relación con la crisis del proceso de paz en Oriente Próximo», Boletín Oficial del Congreso de Diputados, 634, 19 de julio de 2006.

${ }^{71}$ El País, 22-9-2006.

${ }^{72} \mathrm{http}: / /$ www.consilium.europa.eu/ueDocs/cms_Data/docs/pressData/es/ec/92217.pdf 
Estado hebreo. En la sesión de control semanal al gobierno del 20 de octubre, el ministro Moratinos se mostró favorable a «no juzgar» a Israel por la operación Plomo Fundido porque «deseaba mirar al futuro» y las conclusiones de dicho informe podrían tener «consecuencias negativas» a la hora de retomar las negociaciones entre israelíes y palestinos. Según el ministro, el daño provocado por «las guerras, la violencia y el derramamiento de sangre» no se arreglaría «mirando al pasado» ${ }^{73}$.

No obstante, el cambio más drástico se dio con la modificación de la ley de justicia universal. El principio de justicia universal, recogido en el artículo 23.4 de la Ley Orgánica del Poder Judicial de 1985, establecía la competencia de la jurisdicción española para juzgar los delitos de genocidio, lesa humanidad y terrorismo cometidos en el extranjero, aunque fuesen cometidos por personas extranjeras. En 2008 la Audiencia Nacional española admitió diversas querellas contra militares israelíes a los que se responsabilizaba de haber cometido crímenes de guerra. Para evitar una crisis con Israel, el Gobierno Rodríguez Zapatero aprobó la Ley Orgánica 1/2009 que limitó el alcance de este principio exigiéndose que las víctimas tuvieran vínculos con España. Tras esta modificación, el presidente israelí Simon Peres agradeció en persona a Rodríguez Zapatero «que no se llevara a los tribunales a líderes israelíes, tanto civiles como militares, que no han hecho sino defender la vida de su pueblo $»^{74}$.

A su vez, el Gobierno de Rodríguez Zapatero emprendió diversas iniciativas de diplomacia paralela o de segunda vía desarrolladas por la Fundación Tres Culturas de Sevilla y el Centro Internacional para la Paz de Toledo. En el curso de diversos encuentros se reunieron delegaciones palestinas e israelíes que incorporaron a actores no estatatales con el objeto de «anticipar soluciones, ensayar propuestas, probar respuestas y preparar el contexto para la diplomacia oficial para allanar el terreno de las negociaciones oficiales $\rangle^{75}$. El Ministerio de Asuntos Exteriores también promovió diversos encuentros entre la sociedad civil israelí y palestina, como el Foro por una Paz Justa en Oriente Medio (14 de diciembre de 2007) o la Coalición de Madrid (22 de octubre de 2009), aunque sus resultados no siempre fueron positivos, como evidencia la cancelación

73 «Comparecencia del ministro de Asuntos Exteriores y de Cooperación, Miguel Ángel Moratinos Coyaubé, ante la Comisión de Asuntos Exteriores del Congreso, para informar sobre la Asamblea General de Naciones Unidas y de la situación en Oriente Próximo», Boletín Oficial del Congreso de Diputados, 690, 24 de octubre de 2008.

${ }^{74}$ Unos meses antes, el periódico israelí Haaretz explicaba que «Moratinos, a quien antes se miraba en Israel con recelo, e incluso con desprecio, se ha convertido en uno de los elementos más importantes de la reconciliación entre Jerusalén y Madrid... Fue Moratinos quien impulsó en el Parlamento español la legislación que limita rigurosamente la posibilidad de llevar a cabo esos procesos en el futuro y que condujo a la anulación del enjuiciamiento que ya estaba en curso», Haaretz, 01-02-2009.

${ }^{75}$ CASSINELLO, 2008: 7. 
del primero tras las presiones de las autoridades españolas a las organizaciones reunidas para que secundasen la Cumbre de Anápolis ${ }^{76}$.

\section{LA PRESIDENCIA DE RAJOY (2011-2018)}

Tras la victoria electoral del PP, el presidente Mariano Rajoy reafirmó la posición española ante la cuestión palestina, aunque asumió un perfil bajo si lo comparamos con la sobreactuación registrada en las dos legislaturas anteriores $^{77}$. Durante el viaje oficial del presidente Mahmud Abbas a España en diciembre de 2012, Rajoy se mostró a favor de la fórmula de «dos Estados que convivan en paz, en seguridad y en prosperidad», considerando que dicha opción «es algo que tiene en España un carácter histórico y tradicional, que lo apoya la inmensa mayoría de la población española y todos los partidos políticos» y que quiere «la inmensa mayoría de la comunidad internacional, la UE, la práctica totalidad de países de América Latina y EEUU» ${ }^{78}$.

Efectivamente la opinión pública española es claramente partidaria de una solución basada en la solución de los dos Estados y cuenta con una larga trayectoria de solidaridad hacia la cuestión palestina. Una mayoría de los españoles considera que los palestinos deberían disponer de un Estado independiente, tal y como ponen de manifiesto los informes sobre Opinión Pública Española y Política Exterior y de Seguridad elaborados por el Instituto Nacional de Cuestiones Internacionales y Política Exterior (INCIPE) ${ }^{79}$. Al mismo tiempo existe un rico movimiento asociativo que no ha dudado en movilizarse a favor de la cuestión palestina a lo largo de las últimas décadas ${ }^{80}$.

A pesar de que el apoyo español a un Estado palestino independiente y soberano fue reafirmado en diversas ocasiones por el ministro de Asuntos Exteriores José Manuel García-Margallo (2011-2016), lo cierto es que la cooperación al desarrollo hacia los Territorios Ocupados experimentó un drástico recorte como resultado de la crisis económica, reduciéndose en un 85\%. Los cambios originados por la Primavera Árabe en 2011 y la proliferación de conflictos regionales incidieron negativamente en la cuestión palestina, que dejó de ser una prioridad para la diplomacia española.

Probablemente, el reto más importante al que debió enfrentarse Rajoy fue la solicitud de entrada en la ONU del Estado de Palestina el 29 de noviembre de

76 WARCHAWSKI, 2007.

77 BARREÑADA, 2018: 284.

${ }^{78}$ Europa Press, 17-12-2012: http://www.europapress.es/nacional/noticia-oproximoabbas-reune-manana-rajoy-agradecer-apoyo-asamblea-onu-20121217211634.html

${ }^{79}$ INCIPE, 1998; 2003; 2006.

${ }^{80}$ SIRVENT y MARTÍN CARRETERO: 2008: 233-236. 
2012. Tras profundas deliberaciones, España apoyó la candidatura de Palestina como Estado observador de la Asamblea General «por coherencia» con las políticas precedentes. De tal manera se imponían las tesis de García-Margallo, que consideraba que tal respaldo no sólo era acorde con la línea mantenida en las últimas décadas, sino que además era vital para conseguir el respaldo árabe a la candidatura de España al Consejo de Seguridad. Otro factor determinante para entender dicha posición fue la necesidad de proteger las inversiones españolas en el mundo árabe, especialmente en el sector de hidrocarburos y de comunicaciones (y, en particular, el tren de alta velocidad Al-Haramayn de La Meca-Medina).

El 18 de noviembre de 2014 el Congreso de los Diputados aprobó por una abrumadora mayoría (319 síes, una abstención y dos noes) una proposición no de ley presentada por el Grupo Parlamentario Socialista en favor del reconocimiento de Palestina como Estado independiente ${ }^{81}$. Dicha proposición instaba al gobierno a:

1. Reconocer Palestina como Estado, sujeto de Derecho Internacional, reafirmando la convicción de que la única solución posible para el conflicto es la coexistencia de dos Estados, Israel y Palestina. Este reconocimiento debe ser consecuencia de un proceso de negociación entre las partes que garantice la paz y la seguridad para ambas, el respeto a los derechos de los ciudadanos y la estabilidad regional.

2. Promover de manera coordinada en el seno de la Unión Europea dicho reconocimiento del Estado palestino como Estado soberano, en el marco de una solución definitiva y global al proceso de paz en Oriente Próximo basada en la creación de dos Estados, el israelí y el palestino, coexistiendo en paz, seguridad y prosperidad.

3. Buscar en cualquier actuación en este sentido una acción coordinada en concierto con la Comunidad Internacional y en particular con la Unión Europea, teniendo plenamente en cuenta las legítimas preocupaciones, intereses y aspiraciones del Estado de Israel.

4. Hacer valer la pertenencia de España al Consejo de Seguridad para propiciar dicha solución justa y duradera.

A pesar de su aparente rotundidad, debe tenerse en cuenta que esta proposición insistía en la necesidad de que el reconocimiento fuera resultado de un acuerdo entre las partes y supeditaba el reconocimiento pleno del Estado de Palestina a un consenso en el seno de la UE, algo prácticamente inviable dada la disparidad de opiniones existente entre sus 28 miembros.

En enero de 2015, el ministro de Asuntos Exteriores García-Margallo realizó una gira por los países de Oriente Medio en el curso de la cual visitó la

${ }^{81}$ Proposición no de Ley del Grupo Parlamentario Socialista, sobre el reconocimiento del Estado de Palestina, aprobado por el Pleno del Congreso de los Diputados en su sesión del día 18 de noviembre de 2014, Actas del Congreso de los Diputados, expediente 162/001060, http:// www.congreso.es/docu/tramit/LegX/162.1060.pdf 
Franja de Gaza. Poco antes de su viaje concedió una entrevista a la prensa en la que señaló:

La paz es necesaria y urgente. La resolución del conflicto no puede esperar más porque enturbia las relaciones de Occidente con el mundo islámico y envenena la convivencia en la región. Si no se logra la paz, la posición de Mahmud Abbas se verá debilitada, y ello solo beneficiará a los extremistas. La posición de España es que ambas partes deben abstenerse de tomar decisiones unilaterales que dificulten la solución de los dos Estados, la única viable. Es decir, los palestinos no deben judicializar el conflicto y los israelíes frenar los asentamientos en Cisjordania ${ }^{82}$.

\section{CONCLUSIONES}

El conflicto árabe-israelí ha condicionado la política exterior española hacia Oriente Medio. Durante la época franquista se puso el énfasis en las «políticas de sustitución» basadas en la aproximación a Latinoamérica y el mundo árabe para sortear el aislamiento internacional. Una vez rehabilitado, Franco abandonó definitivamente los intentos de acercamiento a Israel y apostó por robustecer las relaciones hispano-árabes, más de manera retórica que efectiva. Tras su muerte se universalizaron las relaciones diplomáticas, pero una vez más el dossier israelí quedó relegado a un segundo plano hasta que en 1986 España se incorporó a la Comunidad Económica Europea y estableció plenas relaciones diplomáticas con Israel.

De manera retrospectiva podemos trazar una línea de continuidad desde la transición hasta nuestros días con ciertas fluctuaciones motivadas por los cambios de gobierno. Probablemente los giros más bruscos los encontramos durante la segunda legislatura del presidente Aznar (en la que el proatlantismo implicó también un mayor alineamiento con las posiciones isrraelíes) y en la primera del presidente Rodríguez Zapatero (marcada por un mayor militantismo hacia la cuestión palestina que, sin embargo, no se tradujo en una mayor interlocución entre las partes). La cooperación española hacia los Territorios Ocupados palestinos es un buen termómetro del compromiso asumido por los diferentes gobiernos, aunque a partir de 2011 experimenta un fuerte retroceso que debe achacarse tanto a la crisis económica como al agotamiento de la fórmula de Oslo.

En cuanto a los actores que intervienen en el proceso de toma de decisiones debe decirse que el Ministerio de Asuntos Exteriores ha gozado de un amplio margen de maniobra, aunque también los presidentes de gobierno han marcado

\footnotetext{
${ }^{82}$ El País, 01-01-2015.
} 
las directrices en momentos concretos. Una buena muestra de ello la representa Calvo-Sotelo que, a diferencia de Suárez, era proclive al establecimiento de relaciones con Israel. Igualmente, el presidente Felipe González era consciente de que debería resolver dicha anomalía antes de que España se incorporara a la Comunidad Económica Europea. También Aznar asumió un claro protagonismo en la delimitación de la política exterior, especialmente después de que los atentados del 11-S motivasen un fortalecimiento del vínculo trasatlántico. Tras su llegada a la Moncloa, Rodríguez Zapatero trató de impulsar un cambio de alianzas internacionales apostando por el multilateralismo, lo que le llevó a adoptar una posición más próxima a la cuestión palestina. Por el contrario, Rajoy mantuvo un perfil bajo en política exterior hacia Oriente Medio concentrándose en la agenda doméstica.

El apoyo español a los derechos nacionales palestinos ha tenido un efecto dinamizador en las relaciones bilaterales hispano-árabes. De hecho, la normalización con Israel no les pasó factura porque España abanderó diversas iniciativas en el seno de la UE a favor del proceso de paz y la creación de un Estado palestino. Tal y como demandaba Israel, las relaciones bilaterales con España no se han convertido en un rehén del proceso de paz. De hecho, la ocupación israelí de los territorios palestinos no ha impedido la intensificación de las relaciones culturales, políticas y económicas hispano-israelíes, especialmente notables en el terreno comercial y tecnológico (seguridad, defensa, investigación, agricultura, energía y medio ambiente) en estas tres últimas décadas.

\section{Bibliografía}

Algora Weber, María Dolores, Las relaciones hispano-árabes durante el aislamiento internacional del régimen de Franco (1946-1950), Madrid, Ministerio de Asuntos Exteriores, 1995. Documentos Diplomáticos, 12.

Algora Weber, María Dolores, «La cuestión palestina y el régimen de Franco», en Ignacio Álvarez-Ossorio e Isaías Barreñada (eds.), España y la cuestión palestina, Madrid, Los Libros de la Catarata, 2003: 19-49.

Álvarez-Ossorio, Ignacio, Informe sobre el conflicto de Palestina. De los Acuerdos de Oslo a la Hoja de Ruta, Madrid, Ediciones del Oriente y el Mediterráneo, 2003.

Álvarez-Ossorio, Ignacio (ed.), «España ante el Gobierno de Hamas», Revista CIDOB d'Afers Internacionals, 79-80 (Barcelona, 2007): 189-206.

Amado Castro, Víctor Manuel, Entre el discurso nacionalista y el compromiso socialista. El laborismo israelí, la internacional socialista y el conflicto árabe-israelí (1947-1983), tesis doctoral, Universidad del País Vasco, 2014.

Aznar, José María, «If Israel goes down, we all go down», The Times, 17-06-2010.

Baer, Alejandro, «Los vacíos de Sefarad. La memoria del Holocausto en España», Política y Sociedad, 38/3 (Madrid, 2011): 501-518. 
Barreñada, Isaías, «La cooperación no gubernamental española con la población palestina», en Ignacio Álvarez-Ossorio e Isaías Barreñada (eds.), España y la cuestión palestina, Madrid, Los Libros de la Catarata, 2003: 197-216.

Barreñada, Isaías (ed.), Entre España y Palestina. Revisión crítica de unas relaciones, Barcelona, Edicions Bellaterra, 2018.

Ben-Ami, Shlomo, La revolución desde arriba. España 1936-1979, Madrid, Riopiedras Ediciones, 1980.

Carlavilla, Mar, «La cooperación gubernamental española con la población palestina», en Ignacio Álvarez-Ossorio e Isaías Barreñada (eds.), España y la cuestión palestina, Madrid, Los Libros de la Catarata, 2003: 173-186.

Cassinello, Emilio, «El Próximo Oriente y la diplomacia de segunda vía», Ponencia presentada al VII Seminario Internacional sobre Seguridad y Defensa en el Mediterráneo. Conflictos regionales y estrategias de seguridad, Barcelona, Fundación CIDOB, 2008.

Córdoba Hernández, Ana María, «El conflicto palestino-israelí visto desde España: oscilaciones y tendencias de la opinión pública», Ámbitos, 20 (Sevilla, 2011): 149-174.

Eiroa San Francisco, Matilde, «El pasado no es suficiente. Temáticas y conflictos en los encuentros de Franco con los líderes árabes y musulmanes», Miscelánea de Estudios Árabes y Hebraicos, 62 (Garana, 2013): 23-46.

Escudero Alday, Rafael (ed.), Segregados y recluidos. Los palestinos y las amenazas a su seguridad, Madrid, Los Libros de la Catarata, 2008.

Feliú, Laura, España y la promoción de los derechos humanos en el Mediterráneo (1996-2007). Un modelo de análisis, Barcelona, Fundación CIDOB, 2009. Documentos Cidob. Mediterráneo y Oriente Medio, 14.

Gillespie, Richard, Spain and the Mediterranian. Developing a European Strategy towards the South, Londres, MacMillan Press, 2000.

Gillespie, Richard, Rodrigo, Fernando y Story, Jonathan (eds.), Las relaciones exteriores de la España democrática, Madrid, Alianza, 1995.

Giménez Piernas, Carlos, «Documentación sobre política exterior», en Revista de Estudios Internacionales, 7 (Santiago de Chile, 1986): 709-744.

González García, Isidro, Relaciones España-Israel y el conflicto de Oriente Medio, Madrid, Biblioteca Nueva, 2001.

González Isidoro, Marta, «Las relaciones diplomáticas entre España e Israel. Pasado, presente y futuro», en Santiago Catalá Rubio, José María Martí y David García Pardo (eds.), Judaismo, Sefarad, Israel, Cuenca, UNED, 2001: 155-166.

Hadas, Samuel, Un legado para la transición, Israel, Madrid, Fundación Transición Española, 2010.

Harel, Víctor, «Dos décadas de relaciones Israel-España: más luces que sombras», en Rein Raanan (ed.), España e Israel. Veinte años después, Madrid, Dykinson, 2007: $37-44$.

Hernando de Larramendi, Miguel y Mañé Estrada, Aurelia (eds.), La política exterior española hacia el Magreb. Actores e intereses, Madrid, Ariel/Real Instituto Elcano, 2009.

INCIPE, La opinión pública española y la política exterior y de seguridad, Madrid, INCIPE, 1998. 
INCIPE, La opinión pública española y la política exterior y de seguridad, Madrid, INCIPE, 2003.

INCIPE, La opinión pública española y la política exterior y de seguridad, Madrid, INCIPE, 2006.

Khader, Bichara, Los hijos de Agenor. Europa y Palestina, desde las cruzadas hasta el siglo XXI, Barcelona, Bellaterra, 2000.

Kienle, Eberhard, «Political Reform through Economic Reform? The Southern Mediterranean States Ten Years after Barcelona», en Haizam Amirah Fernández y Richard Youngs (eds.), The Assessing the Firs Decade, Madrid, Real Instituto Elcano, 2005: 23-34.

Lisbona, José Antonio, España-Israel. Historia de unas relaciones secretas, Madrid, Temas de Hoy, 2002.

Lisbona, José Antonio, «Presiones internas y externas a favor de las relaciones hispano-israelíes durante la democracia (1976-1986)», en Raanan Rein (ed.), España-Israel veinte años después, Madrid, Dyckinson, 2007: 123-136.

Lisbona, José Antonio, Más allá del deber. La respuesta humanitaria del Servicio Exterior frente al Holocausto, Madrid, Ministerio de Asuntos Exteriores, 2015.

López Alonso, Carmen, «Changing Views of Israel and the Israeli-Palestinian Conflict in Democratic Spain (1978-2006)», Center for European Studies, Working Paper (Harvard, 2007): 1-21.

Marquina, Antonio, «Política exterior», en VV. AA., Historia de España. España actual. España y el mundo (1939-1975), Madrid, Gredos, 1995: 511-582.

Mesa, Roberto, La reivención de la política exterior española, Madrid, CEC, 1985.

Miralpeix, Eudaldo, «Factores que condicionan las relaciones hispano-israelíes», en Raanan Rein (ed.), España e Israel. Veinte años después, Madrid, Dykinson, 2007: 27-36.

Morán, Fernando, Una política exterior para España, Barcelona, Planeta, 1980.

Morán, Fernando, España en su sitio, Barcelona, Editorial Plaza y Janés, 1990.

Moratinos, Miguel Ángel, «El triunfo del diálogo en Oriente Medio», El País, 03-051999.

Moratinos, Miguel Ángel, «El Cuarteto de Oriente Próximo: el papel de la Unión Europea y la implicación internacional en el conflicto», en Ignacio Álvarez-Ossorio (ed.), Informe sobre el conflicto de Palestina. De los Acuerdos de Oslo a la Hoja de Ruta, Madrid, Ediciones del Oriente y el Mediterráneo, 2003: 257-268.

Moratinos, Miguel Ángel y León, Bernardino, «España y el proceso de paz de Oriente Medio en el periodo 1975-1995», en Ignacio Álvarez-Ossorio e Isaias Barreñada (eds.), España y la cuestión palestina, Madrid, Los Libros de la Catarata, 2003: 105-124.

Neila, José Luis, España y el Mediterráneo en el siglo XX, Madrid, Sílex, 2011.

Núñez, Jesús, «La política mediterránea de España: necesidad de un propósito de enmienda», Papeles de Cuestiones Internacionales, 85 (Madrid, 2004): 73-80.

Oficina de Información Diplomática, España y los judios, Madrid, Ministerio de Asuntos Exteriores, 1949.

Pérez Mateo, María, «Las relaciones hispano-jordanos en tiempos del régimen franquista: la dimensión cultural y educativa», Revista de Estudios Internacionales Mediterráneos, 3 (Madrid, 2007): 22-44. 
Peters, Joel, «Europe and the Middle East Peace Process: Emerging from the Sidelines» en Stelios Stavridis, Theodore Couloumbis, Thanos Veremis y Neville Waites (eds.), The Foreign Policies of the European Union's Mediterranean States and Applicant Countries in the 1990s, Wiltshire, Macmillan Press, 1999: 295-336.

Portero, Florentino (ed.), «La política exterior de España en el siglo XX», Ayer, 49 (Madrid, 2003).

Portero, Florentino, «Las relaciones hispano-israelíes», Araucaria, 19 (Sevilla, 2008): 179-196.

Ramos Tolosa, Jorge, «La Comisión de Palestina de 1948: la misión imposible de Pablo de Azcárate», Ayer, 93 (Madrid, 2014): 189-213.

Rein, Raanan, Franco, Israel y los judios, Madrid, Consejo Superior de Investigaciones Científicas, 1996.

Rein, Raanan, «Diplomacy, Propaganda, and Humanitarian Gestures: Francoist Spain and Egyptian Jews, 1956-1968», Iberoamericana, 23 (Pittsburgh, 2006): 21-33.

Rein, Raanan (ed.), España-Israel veinte años después, Madrid, Dyckinson, 2007.

Setton, Guy, Spanish-Israeli Relations, 1956-1992: Ghosts of the Past and Contemporary Challenges in the Middle East, Sussex, Sussex Academic Press, 2016.

Sirvent, Luisa y Martín Carretero, José Moisés, «La sociedad civil palestina y las redes de solidaridad internacional», en Rafael Escudero Alday (ed.), Segregados y recluidos. Los palestinos y las amenazas a su seguridad, Madrid, Los Libros de la Catarata, 2008: 219-242.

Thieux, Lawrence y Núñez, Jesús, La cooperación española con el Territorio Palestino Ocupado (1998-2008): ¿una contribución a la paz?, Madrid, Cuadernos del IECAH, 2010.

Viñas, Ángel, «El lastre del pasado y la política exterior en la transición democrática», en Raanan Rein (ed.), España e Israel. Veinte años después, Madrid, Dykinson, 2006: 109-122.

Warchawski, Michael, «Razones por las que no voy a participar en el Foro Social de Madrid por una Paz Justa en Oriente Medio», AlternativeNews.org, 2007: http:// www.rebelion.org/noticia.php?id=60481

Recibido: 18/04/2018

Aceptado: 04/02/2019

Hispania, 2019, vol. LXXIX, nº 261, enero-abril, págs. 221-248, ISSN: 0018-2141, e-ISSN: 1988-8368

https://doi.org/10.3989/hispania.2019.008 